\title{
Control of soleus motoneuron excitability during muscle stretch in man
}

\author{
KAREN L ROBINSON, AJ MCCOMAS, AY BELANGER \\ From the Department of Neurosciences, McMaster University,
}

SUMMARY The relative contributions of intramuscular and extramuscular receptors to changes in the reflex excitability of soleus motoneurons, following muscle stretch, have been studied in man. It was found that reflex excitability was decreased by muscle stretch. The extent of the decrease was related to the amount of stretch, irrespective of whether the latter was produced by dorsiflexion of the ankle or by depression of the Achilles tendon with the ankle joint fixed. The results were unaffected by anaesthesia of the skin. It would appear that neither joint receptors nor cutaneous mechanoreceptors contribute significantly to the decrease in reflex excitability during ankle dorsiflexion and that the intramuscular receptors are mainly responsible for the effects observed.

When a limb is passively moved a number of factors would be expected to adjust the excitability of motoneurons innervating the muscle of that limb. In those muscles which had undergone a change in length there would be alterations in the discharges from the muscle spindles and Golgi tendon organs. In addition, passive movement would change the pattern of activity in joint receptor fibres, while any deformation of the skin around the joint would excite cutaneous mechanoreceptor units. Considerable information is available on the effects of spindle primary and secondary afferents, and of tendon organ inputs, on motoneurons supplying homonymous and antagonist muscles, ${ }^{1-3}$ rather less is known about the reflex actions of cutaneous mechanoreceptors and joint afferents (see Discussion). However, two recent studies suggest that the role of joint receptors may be a significant one. First, inputs from tendon organs and joint receptors have been shown to converge on common interneurons, thereby enhancing motoneuron inhibition. ${ }^{4}$ Secondly, Baxendale and Ferrell ${ }^{5}$ have clearly demonstrated that the thresholds for eliciting the flexion withdrawal and crossed extension reflexes in decerebrate cats are markedly influenced by the position of the knee.

Address for reprint requests: Dr AJ McComas, Neurology, 4U7, McMaster University, Medical Centre, PO Box 2000, Hamilton, Ontario, Canada L8N 3Z5.

Received 1 March 1982

Accepted 9 April 1982

\section{Methods}

The experiments were performed on 10 healthy volunteers (four men, and six women) aged 22-37 years; the study was approved by the Ethics Committee at McMaster University. Two additional subjects were tested but were found unsuitable for inclusion in the study since their $\mathrm{H}$-reflexes were difficult to elicit. The subjects lay prone on a bed with both legs extended and the right leg slightly raised. The right foot was attached with Velcro straps to a wooden foot-plate which was itself fastened to the bed. The foot-plate could be rotated about an axis which passed through the ankle joint and locked in position with a wing-nut. The inclination of the foot-plate to the horizontal plane could be read from a scale. The subjects were asked to relax throughout the testing period and to maintain a constant head position. ${ }^{6}$

\section{Stimulating and recording system}

A $5 \mathrm{~cm} \times 5 \mathrm{~cm}$ lead plate, coated with conducting cream, was applied over the centre of the skin crease in the popliteal fossa. The anodal stimulating electrode was a larger lead plate $(10 \mathrm{~cm} \times 10 \mathrm{~cm})$ which was covered with saline-impregnated gauze and placed underneath the knee. The stimuli were rectangular voltage pulses, $0.5 \mathrm{~ms}$ in duration, delivered from a Devices Ltd stimulator (type 3072) which, in turn, was triggered from a digital timing device (Digitimer type 3290, Devices Ltd). For each subject the stimulus intensity was adjusted so as to evoke an H-reflex of approximately half of the maximal amplitude. This reflex, originally described by Hoffmann,' was the monosynaptic response to an electrically induced impulse volley in homonymous 1 a fibres (see also refs 8,9 ). In addition to eliciting a reflex response, such stimuli were usually sufficient to excite a small fraction of the $\alpha$-motor 
axons directly, producing a compound action potential in the muscle. This potential, the $M$-wave, was used to monitor the consistency of the stimulating conditions.

The $\mathbf{M}$-wave and $\mathbf{H}$-reflex responses in soleus were recorded by means of two chlorided silver-strip electrodes, $3 \mathrm{~cm} \times 6 \mathrm{~mm}$, coated with conducting cream; one was placed in the midline slightly distal to the gastrocnemii and the other was positioned $2.5 \mathrm{~cm}$ below it. The ground electrode, also a chlorided silver-strip, was placed over the outer surface of the lateral condyle of the tibia. EMG activity was amplified and filtered using a $10 \mathrm{~Hz}-1 \mathrm{kHz}$ bandpass and was displayed on a storage oscilloscope (Hewlett-Packard, model 141B) and also averaged with a signal analyser (Hewlett-Packard, model 5480).

\section{Standardisation of muscle stretch}

The principle of the experiment was to stretch the triceps surae (TS) complex by two different methods and to compare the resulting changes in motoneuron excitability. The first method of stretching was to depress the Achilles tendon fully with the foot clamped perpendicular to the tibia. The depression was exerted by the plunger of a $50 \mathrm{ml}$ plastic syringe which was filled with air and connected to a pressure gauge, enabling the pressure $(\mathrm{P})$ to be measured. The longitudinal stretch of TS produced by this manoeuvre was estimated by inserting an hyopodermic needle perpendicularly into the soleus muscle belly and allowing the needle to rotate in front of a protractor as stretch was applied (fig 1A, B). Since the shaft of the needle was anchored in the skin, the latter corresponded to the axis of rotation, the head of the needle tilting away from the heel during stretching. The pressure was then removed from the tendon allowing the needle to resume its vertical position; a determination could then be made of the angle through which the foot-plate had to be rotated (in a dorsiflexed direction) to produce the same deflection of the needle as that caused by the tendon pressure (fig $1 \mathrm{C}$ ). The needle was then withdrawn, partly because its continued presence caused discomfort and partly because repeated manipulation of the ankle joint caused the needle point to lose its original position within the soleus muscle belly.

\section{Experimental procedure}

H-reflexes were elicited with the foot alternately dorsiflexed or in the control position; the amplitudes of 10 responses in each position were measured and averaged. The foot was then clamped perpendicular to the tibia (control position) and a further series of $20 \mathrm{H}$-reflexes were evoked with pressure being applied to the Achilles tendon on alternate occasions. Finally, a third set of 20 measurements was made, the foot being in the control position with a pressure equal to $P$ (see above) being applied to the posterior aspect of the heel (or to one side of the Achilles tendon) on alternate occasions. In each of the three test situations 15 seconds elapsed between successive stimuli to the tibial nerve.

\section{Statistical treatment}

The presentation of conditions was randomised during each experiment. A paired $t$ test was employed to determine the significance of differences between mean values. Throughout the text the mean values have been expressed with the respective standard deviations.

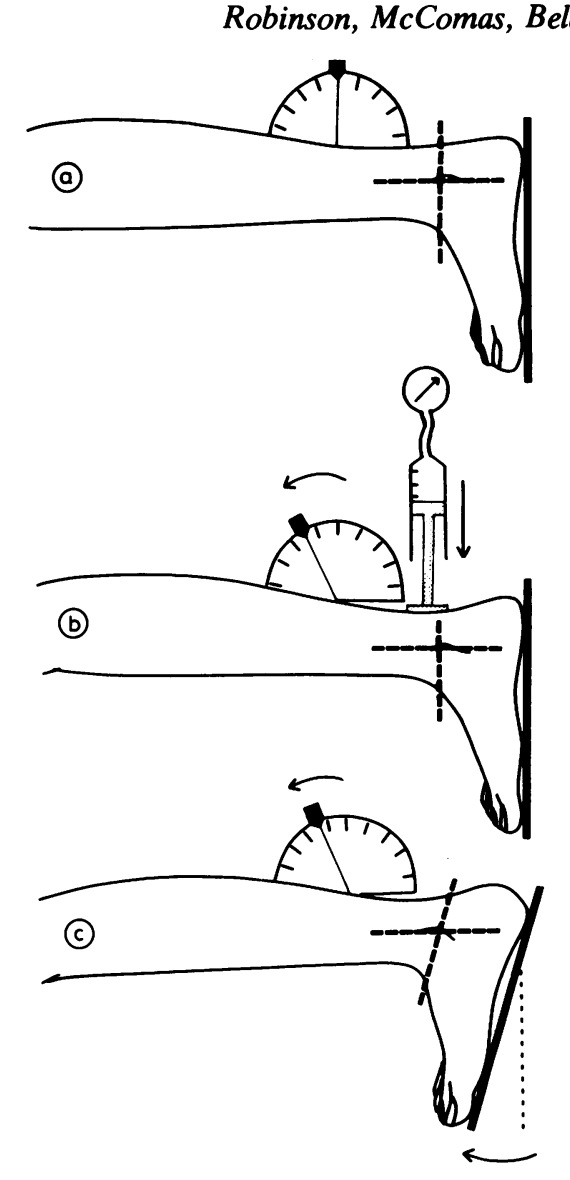

Fig 1 Method for equalising soleus muscle stretch by pressure on Achilles tendon (B) and by ankle dorsiflexion (C); A shows foot in control position. In $\mathrm{B}$ and $\mathrm{C}$ the stretches are adjusted so that the hypodermic needle is deflected from the control position by the same amount.

\section{Results}

\section{(a) EFFECT OF JOINT POSITION}

In keeping with the results of previous studies; 910 dorsiflexion of the ankle produced a reduction in the amplitude of the H-reflex. An example is given in fig 2 in which the sequence of responses in one subject is shown for the control and dorsiflexion positions. Figure 3A shows electronically averaged $\mathrm{H}$-reflexes for the two positions in another subject. This diminution in the $\mathrm{H}$-reflex with dorsiflexion was found in all 10 subjects studied and the mean values differed significantly from the corresponding control results in each $(\mathrm{p}<0.01)$. The mean reduction for the pooled results was $46.9 \pm 19 \cdot 2 \%$ with individual mean values ranging from 19.6 to $79 \cdot 1 \%$. In order to show that the relationship between joint 


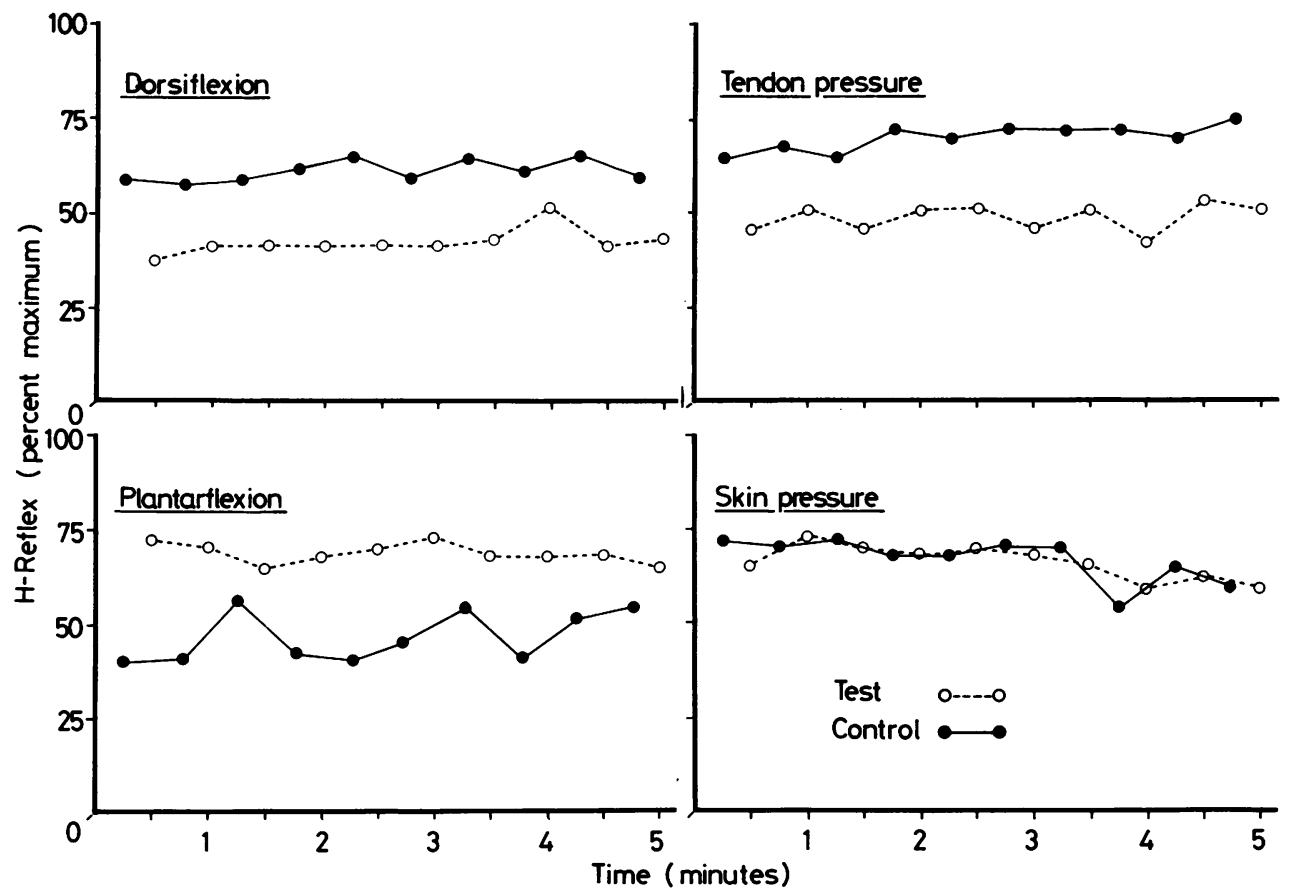

Fig 2 Relative H-reflex amplitudes in a 29-year-old female subject during four experimental conditions. For each situation the test procedure (solid lines) was alternated with observations made with the foot in the control position (interrupted lines).

Female 25years

Dorsitlexion

(a)

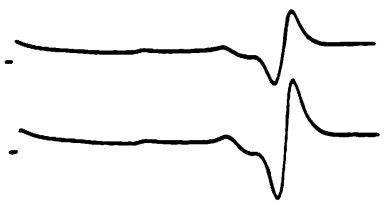

Tendon pressure

(b)

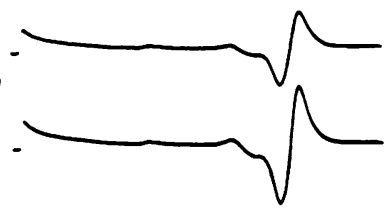

Skin pressure

(c)

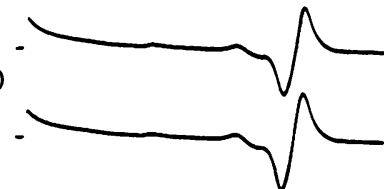

Male 25years

Tendon pressure

(d)

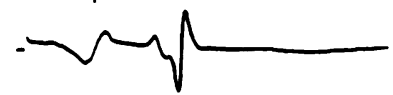

(e)

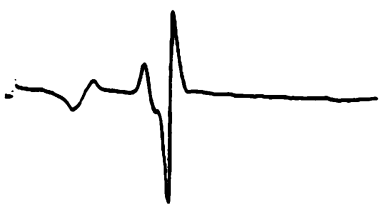

Tendon pressure (skin anaesthetised)

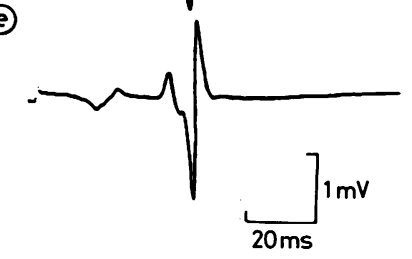

Fig 3 Averaged $H$-reflex responses in a 25-year-old female subject during dorsiflexion (a), depression of Achilles tendon (b) and pressure over the skin (c). In another subject, a 25-year-old man, pressure was applied over the Achilles tendon before (d) and after (e) anaesthetisation of the skin. In each pair of records $(a-e)$ the upper and lower traces show the test and control situations respectively. 
position and $\mathrm{H}$-reflex amplitude was a continuous one, the results of plantarflexion were also studied. When the foot of each subject was plantarflexed by $5-15^{\circ}$ (mean $8.7 \pm 3.0^{\circ}$ ) it was possible to augment the $\mathrm{H}$-reflex in nine of the 10 subjects, the overall increase for the entire population being 51.9 \pm $42 \cdot 1 \%$. In six of the nine subjects displaying augmentation the mean change in H-reflex amplitude was significant at the $0 \cdot 01$ level (fig 4).

(b) EFFECTS OF PRESSURE ON TENDON AND SKIN In all 10 subjects the effect of depressing the Achilles tendon was to reduce the amplitude of the H-reflex $(p<0.01)$, the mean reduction being 37.1 $\pm 15.8 \%$ (range $24.8 \%$ to $78.5 \%$ ). When the same pressure was applied to the skin to either side of the tendon or over the heel, no change in the H-reflex amplitude was noted in seven subjects; in two there was a decrease and in one there was an increase. When the results for the 10 subjects were pooled the mean result was $3.7 \pm 1.5 \%$ less than the control value, a statistically insignificant difference. The series of results of pressing on the skin and on tendon respectively are shown for one subject in fig 2 with the average values for another subject being depicted in fig $3(\mathrm{~B}, \mathrm{C})$.

The largely negative results of skin pressure were confirmed by two further experiments in which the skin over the Achilles tendon was infiltrated with local anaesthetic, so that pricking and light touch could not be detected. In both subjects pressure

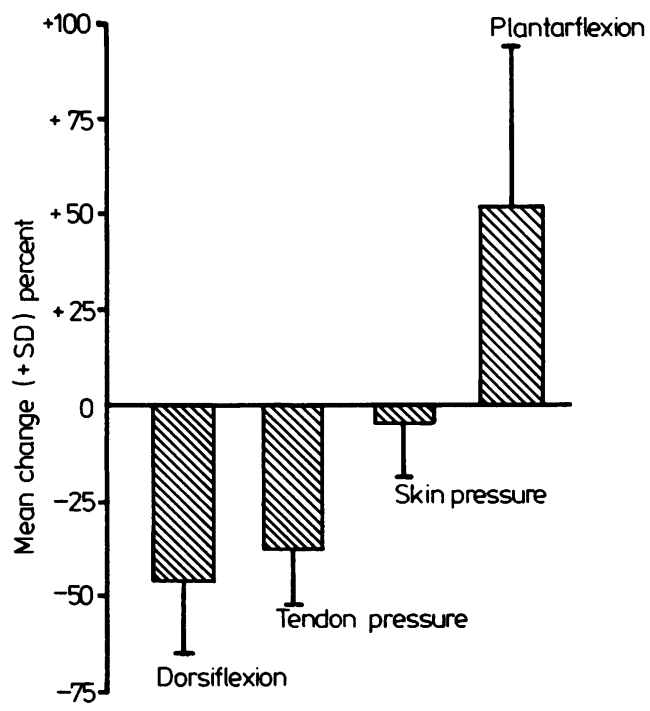

Fig 4 Mean percentage change (+1 SD) in $H$-reflex amplitude for 10 subjects following each of the four experimental procedures (see text). over this area of skin, so as to depress the Achilles tendon and stretch TS, was as effective in diminishing the $\mathrm{H}$-reflex as in the absence of cutaneous anaesthesia (fig 3D, E).

In fig 4 the mean values for the pooled results are shown for each of the four experimental conditions, that is, dorsiflexion and plantarflexion of the ankle and pressure applied to the tendon and skin.

\section{Discussion}

In confirmation of the earlier results of Magladery, Teasdall, Park \& Porter, "1 Paillard, ${ }^{9}$ and of Engelhorn \& Hoffman ${ }^{10}$ the present experiments have shown that the excitability of human soleus motoneurons, as reflected in the $\mathrm{H}$-reflex, is markedly affected by the position of the ankle joint. When the ankle is moved from its midposition into dorsiflexion, motoneuron excitability decreases; conversely, plantarflexion brings about an increase in excitability. The purpose of the study was to determine to what extent the effect of dorsiflexing the ankle might depend on activity in receptors lying outside the triceps surae complex, either in the capsule of the ankle joint or in the skin over the joint. Previous studies, undertaken in animal preparations, did not enable the reflex effects of either type of afferent to be predicted with confidence. Thus, most of the studies of joint receptor effects in animals have been performed with single electrical stimuli to articular nerves. ${ }^{1213}$ The use of more natural stimuli has produced small or variable effects. ${ }^{1214}$ The type of preparation used in such studies was also shown to be of crucial significance since contrasting effects could be obtained in animals with spinal and pontine lesions respectively. ${ }^{15}$ The range of joint movement is also important in considering the possible role of joint afferents since it is known from single fibre recordings that the majority of units are only responsive to extreme joint position. ${ }^{16}$ Although small changes in joint angle were employed in the present experiments, the ankle was brought close to the limit of dorsiflexion by the extended position of the knee and the consequent stretch of the gastrocnemii.

The possible contribution of cutaneous afferents to the observed results must also be considered since mechanoreceptors in the skin over the dorsum of the ankle would have been compressed by the dorsiflexion. In the present experiment receptors in the sole of the foot would also have been activated, due to the pressure of the foot-plate as the ankle was dorsiflexed. It is known that alternating sequences of excitation and inhibition can be evoked in human motoneuron pools following small indentations of the skin, ${ }^{17}$ but such stimuli have involved transient 
deformations rather than the steady ones which would have occurred in these experiments.

The present study resolves uncertainties regarding the possible roles of skin and joint afferents by demonstrating that muscle stretch, produced by pressure over the Achilles tendon, causes almost as much motoneuron inhibition as stretch produced by ankle dorsiflexion. Pressure on the tendon was also found to induce inhibition in normal subjects by Mark, Coquery \& Paillard, ${ }^{18}$ Burke, Andrews \& Ashby ${ }^{19}$ and Delwaide; ${ }^{20}$ however, in none of these studies was the amount of muscle stretch monitored and little information was given concerning the extent of the resulting inhibition. Angel \& Hofmann $^{21}$ also investigated passive dorsiflexion and plantarflexion combined with the $\mathrm{H}$-reflex but they admitted to methodological difficulties which would have influenced their results. The interpretation of the present results is that the receptors responsible for the decrease in reflex excitability lay within the stretched muscle and that any effects of skin and joint afferents were relatively slight. The nature of the intramuscular receptor responsible for the inhibition could not be determined from these experiments and it is therefore possible that either, or both, of the two main types, that is, muscle spindle and Golgi tendon organs, were involved. Thus the tendon organs are known to inhibit homonymous motoneurons through a pathway containing one or two interneurons. ${ }^{22}$ Although early investigations of these receptors indicated that they were rather insensitive to passive stretch, ${ }^{23}{ }^{24}$ low thresholds have been found in some of the more recent studies in the cat (for example ${ }^{2526}$ ). In the present study dorsiflexions as small as $2^{\circ}$ were sufficient to reduce the H-reflexes to half or less of their initial amplitude in three of the 10 subjects; in the entire sample a mean dorsiflexion of $4^{\circ}$ reduced the $\mathrm{H}$-reflex by $37 \%$. Despite the small amount of ankle movement, the passive tension induced in the triceps surae muscle would have been relatively large; thus passive tension rises steeply when the ankle joint is close to its limit of dorsiflexion, as in the present experiments. ${ }^{27}$ Since the tendon organs are responsible to changes in tension rather than length, it is conceivable that they had been excited by the stimuli employed.

The other potential cause of diminished motoneuron excitation in these experiments would be presynaptic inhibition of the 1a terminals following impulse activity evoked in the same fibres by muscle stretch. Indirect evidence indicates that inhibition of this kind, originally demonstrated in anaesthetised or decerebrate cats ${ }^{128}$ is also a feature of spinal reflex activity in conscious man. ${ }^{20} 29$ Preliminary experiments, in which voluntary activation of motoneurons was employed as the testing procedure during passive dorsiflexion, suggested that presynaptic inhibition may well have been responsible for part of the effects observed in the present study $\left(\mathrm{cf}^{20}\right)$.

The authors gratefully acknowledge the technical assistance of Glenn Shine and the secretarial skills of Judith Moffatt.

\section{References}

' Eccles JC. The Physiology of Synapses. Berlin: Springer, 1964.

${ }^{2}$ Houk JC, Singer JJ, Henneman E. Adequate stimulus for tendon organs with observations on mechanics of ankle joint. J Neurophysiol 1971;34:1051-65.

${ }^{3}$ Kirkwood PA, Sears TA. Monosynaptic excitation of motoneurones from secondary endings of muscle spindles. Nature 1974;252:243-4.

${ }^{4}$ Lundberg A, Malmgren K, Schomburg ED. Role of joint afferents in motor control exemplified by effects on reflex pathways from $1 \mathrm{~b}$ afferents. $J$ Physiol (Lond) 1978;284:327-43.

${ }^{5}$ Baxendale RH, Ferrell WR. The effect of knee joint afferent discharge on transmission in flexion reflex pathways in decerebrate cats. $J$ Physiol (Lond) $1981 ; 315: 231-42$.

${ }^{6}$ Hayes KC, Sullivan J. Tonic neck influence on tendon and Hoffmann reflexes in man. Electromyogr Clin Neurophysiol 1976;16:251-61.

${ }^{7}$ Hoffmann P. Uber die Beziehungen der Sehnenreflexe zur willikurlichen Bewegung und zum Tonus. $Z$ Biol 1918;68:351-70.

${ }^{8}$ Magladery JW, Porter WE, Park AM, Teasdall RD. Electrophysiological studies of nerve reflex activity in normal man. IV. The two-neurone reflex and identification of certain action potentials from spinal roots and cord. Bull Johns Hop Hosp 1951;88:499519.

9 Paillard J. Functional organization of afferent innervation of muscle studied in man by monosynaptic testing. Am J Phys Med 1959;38:239-47.

${ }^{10}$ Engelhorn R, Hoffman FA. Muskeldehnung als Hemmungsfaktor der Eigenreflexe beim Menschen. Dtsch Z Nervenheilk 1953;171:161-8.

"Magladery JW, Teasdall RD, Park AM, Porter WE. Electrophysiological studies of nerve and reflex activity in normal man. V. Excitation and inhibition of two-neurone reflexes by afferent impulses in the same nerve trunk. Bull Johns Hop Hosp 1951;88:520-37.

12 Skoglund A. Anatomical and physiological studies of knee joint innervation in the cat. Acta Physiol Scand 1956;36:suppl. 124, 101P.

${ }^{13}$ Eccles RM, Lundberg A. Synaptic actions in motoneurones by afferents which may evoke the flexion reflex. Archs Ital Biol 1959;97:199-221.

14 Cohen LA, Cohen ML. Arthrokinetic refiex of the knee. Am J Physiol 1956;184:433-7.

is Holmqvist B, Lundberg A. Differential supraspinal control of synaptic actions evoked by volleys in the flexion 
reflex afferents in alpha motoneurones. Acta Physiol Scand 1961;54:suppl. 186, 51P.

${ }^{16}$ Burgess PR, Clark FJ. Characteristics of knee joint receptors in the cat $J$ Physiol (Lond) 1969;203:31735.

${ }^{17}$ Caccia MR, McComas AJ, Upton ARM, Blogg T. Cutaneous reflexes in small muscles of the hand. $J$ Neurol Neurosurg Psychiatry 1973;36:960-77.

${ }^{18}$ Mark RF, Coquery JM, Paillard J. Autogenetic reflex effects of slow or steady stretch of the calf muscles in man. Exp Brain Res 1968;6:130-45.

${ }^{19}$ Burke D, Andrews C, Ashby P. Autogenic effects of static muscle stretch in spastic man. Arch Neurol 1971;25:367-72.

${ }^{20}$ Delwaide PJ. Human monosynaptic reflexes and presynaptic inhibition. An interpretation of spastic hyperreflexia. In: Desmedt JE, ed. New Developments in Electromyography and Clinical Neurophysiology Basel: Karger, 1973;3:508-22P.

${ }^{21}$ Angel RW, Hofmann WW. The H-reflex in normal, spastic and rigid subjects. Arch Neurol 1963;8:591-6.

${ }^{22}$ Eccles JC, Eccles RM, Lundberg A. Synaptic actions on motoneurones caused by impulses in Golgi tendon organ afferents. J Physiol (Lond) 1957;138:227-52.

${ }^{23}$ Matthews BHC. Nerve endings in mammalian muscle. $J$ Physiol (Lond) 1933;78:1-53.

${ }^{24}$ Hunt CC, Kuffler SW. Stretch receptor discharges during muscle contraction. J Physiol (Lond) 1951; 113:298-315.

${ }^{25}$ Alnaes E. Static and dynamic properties of Golgi tendon organs in the anterior tibial and soleus muscles of the cat. Acta Physiol Scand 1967;70:176-87.

${ }^{26}$ Stuart DG, Goslow GE, Mosher CG, Reinking RM. Stretch responsiveness of Golgi tendon organs. Exp Brain Res 1970;10:463-76.

${ }^{27}$ Tardieu C, Colbeau-Justin P, Bret MD, Lespargot A, Tardieu G. Effects on torque angle curve of differences between the recorded tibia-calcaneal angle and the true anatomical angle. Eur J Applied Physiol 1981;46:41-6.

${ }^{28}$ Frank K, Fuortes MG. Presynaptic and postsynaptic inhibition of monosynaptic reflexes. Fed Proc 1957;16:39-40.

${ }^{29}$ Burke D, Ashby P. Are spinal 'presynaptic' inhibitory mechanisms suppressed in spasticity? J Neurol Sci 1972;15:321-6. 